\title{
Cervical Cancer Screening in Selangor, Malaysia
}

\author{
Nik Nairan Abdullah, Waqar Al-Kubaisy, Mazlin Mohamad Mokhtar \\ Population Health \& Preventive Medicine, Faculty of Medicine, \\ UniversitiTeknologi MARA (UiTM),SungaiBuloh,Malaysia. \\ niknairan@yahoo.com
}

\begin{abstract}
A total of 384 females aged 20 years and above from two urban health centres in Selangor were recruited to determine the cervical cancer screening behaviours.Researchers used a set of questionnaires to collect data. The prevalence of ever undergone Pap smear was $58.1 \%$. Working commitment was a significant barrier to performing Pap smear among non-performers with higher educational level relative to those with lower educational level. Non- Malays were four times more likely to perceive cost as a barrier. Older women perceivedworry due to Pap smear less likely compared to those younger.
\end{abstract}

Keywords: urban;cervicalcancer;screening;barriers.

eISSN: 2398-4295 @ 2017. The Authors. Published for AMER ABRA by e-International Publishing House, Ltd., UK. This is an open access article under the CC BY-NC-ND license (http:///creativecommons.org/licenses/by-nc$n d / 4.0)$. Peer-review under responsibility of AMER (Association of Malaysian Environment-Behaviour Researchers), ABRA (Association of Behavioural Researchers on Asians) and CE-Bs (Centre for EnvironmentBehaviour Studies), Faculty of Architecture, Planning \& Surveying, UniversitiTeknologi MARA, Malaysia.

https://doi.org/10.21834/ajbes.v2i6.32 


\subsection{Introduction}

Cervical cancer is one of the most preventable types of cancer (Bazarra-Fernandez,2010). Currently, it is the $7^{\text {th }}$ most common cancer worldwide and the second most common cancer in women (Nelas et al.,2015). Half of the women who get cervical cancer are between 30 and 55 years old (Bazarra-Fernandez,2010)

Changes can be found in the cervix when they are still precancerous (BazarraFernandez,2010),hence screening is most appropriate. Nelas et al. (2015) stated that promoting adherence to screening is a key strategy. The proven screening method for the early detection of cervical cancer is cervical cytological examination using the Papanicolou's stain referred to as Pap smear examination. The Pap smear was discovered in the 1940's and introduced to the developed countries in the 1960's. The objective of the test is to detect pre-cancerous lesions at the cervix and endocervical canal. Wan Putih et al.(2011) reported that the national coverage of Pap smear in 2006 was low (43.7\%) despite it is provided free of charge at governmental health facilities. Therefore, there is a need to identify the barriers that might explain the reasons some women were less likely to undergo cancer screening.Furthermore, Farokhzadian \& Shahrbabaki (2014) emphasized that it is necessary to collect enough information about health behaviour in the society to change the health behaviour.Hence, this is the basis of our rationale for conducting the study.

The purpose of the study was to determine the prevalence of ever Pap smear uptake and socio-demographic factors associated with barriers among women who did not undergo Pap smear or had previous Pap smear more than three years ago.

\subsection{Literature Review}

Awang-Shuib,Sahari and Ali (2012) defined culture, or ethnic identity comprises specific values, beliefs, norms and attitude, shared among group members.Cultural beliefs and norms are known to influence participation in early detection and screening services, and these elements are significant in human behavioural studies (Wong et al.,2008).As in all health situations,women's attitudes towards screening are of utmost importance (Nelas et al.,2015).

Studies have documented several factors that gave rise to the low uptake of Pap smear (Fylan,1998\&Wong et al., 2008).Fylan (1998) stated that women of low socio-economic status may be less likely to be screened. Furthermore, low education level resulted in a lack of knowledge about the benefits of screening

The health belief on screening influences the uptake of Pap smear.Ferreira et al. (2016) described low belief in the vulnerability of getting cancer hinders adherence to screening. Similarly,perceived susceptibility to cancer and perceived obstacles are predictors of cervical cancer behavior as reported by Fylan (1998). Fylan (1998) also documented that it is important to determine ethnicity-related reasons for non-participation for example ethnic- 
minority population of Asian origin were less likely to participate in health screening programmes. In Wong et al.'s (2008) study, cultural and religious beliefs such as family commitment play a vital role in the decision to participate in screening activities among Asian women. Other barriers such as pain and fear of cancer detection have also been documented by Fylan (1998). Fylan (1998) stressed that receipt of abnormal result from Pap smear test will cause a high level of stress among women.

\subsection{Methodology}

This survey was conducted in Selangor state of Malaysia. Selangor consisted of eight health districts. One of the districts is Gombak and it has eight health centres. Two health centres were chosen randomly. A cross-sectional study was carried out during the working days in the month of November 2012. The inclusion criteria were females aged 20 years and above, Malaysian citizens and able to communicate in either English or Bahasa Malaysia.

Trained researchers approached a sample size of 432 women who fulfilled the inclusion criteria randomly while they were waiting to be examined by the health personnel. The researchers explained the nature of the study to each of the women and asked whether she was willing to participate in order to get consent. Participation was voluntary. If the woman agreed, verbal consent was taken and researchers then proceeded to the interviewing session with lasted between 15-20 minutes. The researchers using standard questionnaires interviewed each participant.

The questionnaires contained information on socio-demographic characteristics (age, ethnicity, highest education level, household income), uptake of Pap smear (ever, never and previous Pap smear more than three years ago). For participants who never undergo Pap smear or had the last Pap smear three years ago were given additional questions on perceived barriers. There were eight statements on perceived barriers such as pain, worry due to Pap smear, embarrassment, non-consent from partner, working commitment, family commitment that do not allow for free time to do Pap smear, perceived cost and lazy/not botheredto do Pap smear. For each barrier, score of 0 was given for "no" answers while a positive answer gave a score of 1 . Therefore, if the women answered "yes" to all eight perceived barriers, she will get a score of 8 . Ethical approval was obtained from the ethics committee of the UniversitiTeknologi MARA (UiTM).

Data were entered in SPSS Version 18.0 and data cleaning was conducted before proceeding to analysis. All questionnaires collected in the study were analysed. The sociodemographic information was presented in frequency and percentages (\%).Chi-square tests were performed to determine the association between factors and barriers. We considered $p \leq 0.05$ as a level of significance. In addition, the strength of association was evaluated by calculating the odds ratio $(\mathrm{OR})$ and $95 \%$ confidence interval $(\mathrm{Cl})$.Univariate analysis was performed followed by multivariate analysis for the outcome. 


\subsection{Results and Discussions}

Out of 432 , only 384 women agreed to continue with the interviewing. Although the response rate of $89 \%$ was good, nevertheless we visualize the rate to be higher because cervical cancer is a serious female health problem. The mean age of the participant was $37.65+11.45$ ranging from 20-76 years old. Most of the participants were Malays $(80.7 \%)$ followed by non-Malays (Table 1$)$. The majority were married, $n=327(85.16 \%)$ followed by single, $n=33(8.59 \%)$ while divorced/widowed women was $6.25 \%$. The prevalence of ever undergone Pap smear was 223/384 (58.1\%). Therefore, our rate is higherthan the national survey $(43.7 \%$ ). Most probably this could be attributed to the different sample (our population is only confined to health centres) and the improved level of awareness about Pap smear among women during these six year period (Wan Putih et al.,2011). In addition, confusion among our participants between Pap smear and vaginal swabs could have resulted in this high rate.

From the descriptive analysis, worry due to Pap smear, pain and embarrassment were the common perceived barriers among women who either did not undergo Pap smear or had it more than three years ago, with worry being the most common, 129/263(49.0\%).Least common barrier was cost, 24/251(9.5\%). Regarding the barrier scores, we found that the mean score of perceived barriers was $2.12+1.68$ (total score range from 0-7).

The mean barrier score is relatively low. However, our result gives a positive indicator that the women studied faced minimal barriers towards Pap smear performance. Hence, there may be other factors that may deter these women from undergoing the screening.

Our study showed that there is a significant association betweeneducational level and working commitment. Women who attained tertiary education level were more likely to perceive working commitment as a barrier for undergoing Pap smear compared to those with lower education, $\mathrm{OR}=2.96,95 \% \mathrm{Cl}=1.67-5.26$. Women with higher education level should be more aware of the risk of cancer and the benefits of Pap smear. Furthermore, women who had total household income RM3001 and above perceived working commitment three times more likely as a barrier relative to those earning RM3000 and less, $\mathrm{OR}=3.02,95 \% \mathrm{Cl}=1.63-5.63$. Hence, both of our findings corresponded to each other. However, after we the multivariate analysis was performed, our study revealed that only working commitment was a significant barrier to performing Pap smear among women with higher household income relative to those in the lower income level, AOR $=2.11,95 \% \mathrm{Cl}=1.06-4.19$. Refer Table 2 .

Women in higher socio-economic group probable are preoccupied with work and this will hinder them to get time off for their healthcare (Baharom and Ismail, 2008). Our finding contradicted to Fylan (1998) who documented that women in the lower socio-economic group were less likely to be screened. Besides that, male management staff was identified as a barrier to screening according to Baharom and Ismail (2008). Therefore, Fylan (1998) recommended that convenient clinic time may reduce the barrier for those working. 
We were unable to compute the magnitude of the association between total household income level and perceived cost because there was no participants in the higher income group who answered 'yes' for perceived cost.

Non- Malays were more likely to perceive cost as a significant barrier compared to Malays, $\mathrm{OR}=3.08,95 \% \mathrm{Cl}=1.25-7.56$. On the other hand, they were less likely to perceive working commitment as a barrier compared to the Malays, $\mathrm{OR}=0.42,95 \% \mathrm{Cl}=0.18-0.99$. In the multivariate analysis, non- Malays were four times more likely to perceive cost as a barrier however working commitment, $\mathrm{AOR}=3.99,95 \% \mathrm{Cl}=1.27-12.54$ was no longer a barrier. Non-Malays may perceive that Pap smear requires cost because most probably they utilized more of the private facilities that demand higher cost compared to governmental health centres. This is because patients attending government clinic faced problems with long waiting time, large crowd,and limited parking space. As a result, they choose to go to a private clinic at their convenient time according to Baharom and Ismail (2008).Moreover, they might not be aware that there is no cost incurred for having Pap smear in the governmental health clinics.

On the other hand, non-Malays health-seeking behaviours are somewhat different from the Malays. It is interesting to acknowledge that for breast cancer patients, Malay women with larger tumours presented at a later stage than other ethnic groups as documented by Hisham and Yip (2004). Strong belief in traditional medicine besides negative perceptions about the disease may contribute to the cultural variations.

For women aged 40 and above, they were less likely to perceive having a Pap smear makes them worry, $\mathrm{OR}=0.56, \quad 95 \% \mathrm{Cl}=0.34-0.92$ and working commitment, $\mathrm{OR}=0.45,95 \% \mathrm{Cl}=0.24-0.84$ as barriers relative to younger age group. In the final analysis, only worry remained as a significant barrier, $\mathrm{AOR}=0.50,95 \% \mathrm{Cl}=0.27-0.91$. Nelas et al. (2015) also documented that women expressed fear of receiving Pap smear result.

Older age women were no longer working;hence have more free time for health care. But on the other hand, younger women will tend to worry more becausethe fear of getting cancer at the genital organ because as they aresexually active. In addition, they may be more educated about the effects of screening compared to those older. Being in the reproductive age group and working actively make them more likely to become worried if they get sick. Some may believe that there is no hope for cure and death is inevitable when cancer is diagnosed as suggested by Wong et al.(2008).In view of this, there is a need to reduce worry in women receiving abnormal smear results by giving an explanation the meaning of such result as suggested by Fylan (1998). It is fundamental that health professionals educate women on to adopt healthy attitudes towards screening (Ferreira et al.,2016).

We didn't detect other perceived barriers such as pain, embarrassment to be significant unlike in Wong et al. (2008) study that found such factors to have an impact on screening. We found that embarrassment did not hinder women from participation because the presence of female health cares providers in performing Pap smear tests. Even though 
Wong et al.(2008) reported that family needs are of a priority than one's health especially among Asian women, we didn't find similar barrier to be significant in our study.

We did not find the family as a significant barrier because women are empoweredin making a decision in their life,particularly our sample population is urban women. This is consistent with Baharom\&lsmail (2008)'s study which documented that women have freedom of movement, empowerment and financial freedom however these did not guarantee that they would practice preventive health care.

There are several limitations to our study that gave rise to the above findings. The majority of the participant were predominantly Malays. However, we acknowledge that language barrier experienced among the researchers and the non-Malays female health attendees may contribute to the recruitment of the study population. We did not verify selfreported Pap smear uptake with clinical records.Participants were also subjected to recall bias in relation to the practice of Pap smear. We could not extrapolate the finding to the general population because our sample is confined to health centres.Larger respondents are required to examine the impact of cultural diversity interactions and awareness the differences among the multicultural society especially in East Malaysia (Awang-Shuib et al, 2012).

\subsection{Conclusion}

Older women were less likely to perceive worry as a barrier to undergo Pap smear relative to younger women. Women with higher household income were more likely to perceive working commitment as barrier compared to those with lesser household income.

\section{Acknowledgement}

We thank Research Management Institute (RMI) of UniversitiTeknologi MARA (UiTM) for granting the research fund (600-RMI/DANA 5/3/RIF (356/2012). In addition, we thank Selangor Health Department and Gombak Health District Office for giving us the permission to conduct the study.

\section{References}

Baharom,A.,\&lsmail,M.(2008).Case studies on Decision for cervical cancer screening among working women. The Journal of Human Resource and Adult Learning,4(2),173-184.

Bazarra-Fernandez, A. (2010). Cervical cancer: education for everybody.Procedia-Social and Behavioral Sciences, 2(2), 229-233.

Farokhzadian, J., \&Shahrbabaki, P. M. (2014). Survey of Women's Knowledge, Attitude and Practice Regarding Prevention of Common Genital Tract Infection. Procedia-Social and Behavioral Sciences, 136, 381-384. 
Ferreira, M., Ferreira, S., Ferreira, N., Andrade, J., Chaves, C., \& Duarte, J. (2016).Lifestyles and Surveillance of Sexual and Reproductive Women's Health. Procedia-Social and Behavioral Sciences, 217, 1019-1027.

Fylan,F.(1998).Screening for cervical cancer:a review of women's attitudes,knowledge,andbehaviour.British Journal of General Practice,48,1509-1514.

Hisham, AN., \& Yip, CH.(2004).Overview of breast cancer in Malaysian women: a problem with late diagnosis. Asian J Surg.,27(2),130-133.

Nelas, P., Duarte, J., Chaves, C., Coutinho, E., \&Amaral, O. (2015). Health beliefs about cervical cancer in university students. Procedia-Social and Behavioral Sciences, 165, 189-194.

Wan Putih, SE.,Samsuddin,NR., Syed Hussain, SNA., Azhar Shah, S., Aljunid,SM. (2011). HPV Positivity and its' Influencing Factors among Invasive Cervical Cancer Women in Malaysia.International Journal of Public Health Research ,1(1), 13-22.

Wong, LP., Wong, YL., Low, WY., Khoo, EM.,\&Shuib, R. (2008).Cervical cancer screening attitudes and beliefs of Malaysian women who never had a Pap smear: aqualitativestudy. International Journal of Behavioural Medicine,15,289-292 